Case Report

\title{
Unusual case of internal resorption in cervical region of maxillary left lateral incisor
}

\author{
Kazuhiko Nakano*1, Noriko Shimizu*1, Takashi Komura*2 and Takashi Ooshima*1 \\ *1 Department of Pediatric Dentistry, Osaka University Graduate School of Dentistry \\ 1-8 Yamada-oka, Suita, Osaka 565-0871, JAPAN \\ *2 Komura Pedodontics and Orthodontics \\ 5-14-4 Naka-Sakurazuka, Toyonaka, Osaka 561-0881, JAPAN
}

\begin{abstract}
We treated an unusual case of internal resorption of the maxillary left lateral incisor seen in a 15-year-old female. The patient was referred to our clinic complaining of repeated cold pain and spontaneous pain in the maxillary left lateral incisor region. An intraoral examination revealed that the tooth was a microdont with a large tubercle, with a pink spot observed in the mesiopalatal area, while radiograph revealed an unusual radiolucent lesion in the cervical area of the affected tooth. Our diagnosis was internal resorption and the affected tooth symptoms ceased after a pulpectomy was performed. Over the next 3 years, periodical examinations performed at 3-month intervals did not reveal further resorption.
\end{abstract}

Key words

Internal resorption, Maxillary lateral incisor, Pulpectomy

\section{Introduction}

Tooth resorption is generally differentiated into internal or external resorption ${ }^{1)}$. Internal resorption, which is typically asymptomatic, can be identified using routine radiographic examinations as a uniform round to oval enlargement of the $\mathrm{canal}^{2}$, though it is often misdiagnosed as external root resorption $^{3}$. Further, a pink discoloration can be identified when the internal resorption is located in the coronal region. External resorption has been classified as external surface resorption, external inflammatory root resorption, replacement resorption, and ankylosis ${ }^{1)}$, and can be further divided into invasive cervical resorption, which is an uncommon form of external resorption without any external signs, that is usually detected by a routine radiographic examination ${ }^{4}$. Such invasive cervical resorption has also been termed internal-external resorption $^{5)}$, extracanal root resorption ${ }^{6}$, and cervical external resorption ${ }^{7}$, and its clinical features are

Received on July 20, 2004

Accepted on October 15, 2004 known to be similar to those of internal resorption, such as a pink coronal discoloration, and absence of pain, except in cases with pulpal or periodontal infection, while the radiographic features are also comparable ${ }^{4}$. The major difference between invasive cervical resorption and internal resorption is that the former is initiated by a periodontal lesion, which can be identified in a clinical examination ${ }^{8)}$.

Herein, we report a rare case of cervical internal resorption of the maxillary lateral incisor treated in a 15-year-old female patient.

\section{Case report}

A 15-year-old female was referred to the Pedodontic Clinic of Osaka University Dental Hospital with the chief complaint of cold pain in the maxillary left lateral incisor region. She underwent operations at 4Y2M (lip closure) and 10Y2M (bone grafting) for a cleft lip and palate in the left palatal region. At the time of the initial visit, she had been receiving orthodontic treatment and the affected tooth was under traction, though there were no other apparent health problems. An oral examination revealed that 


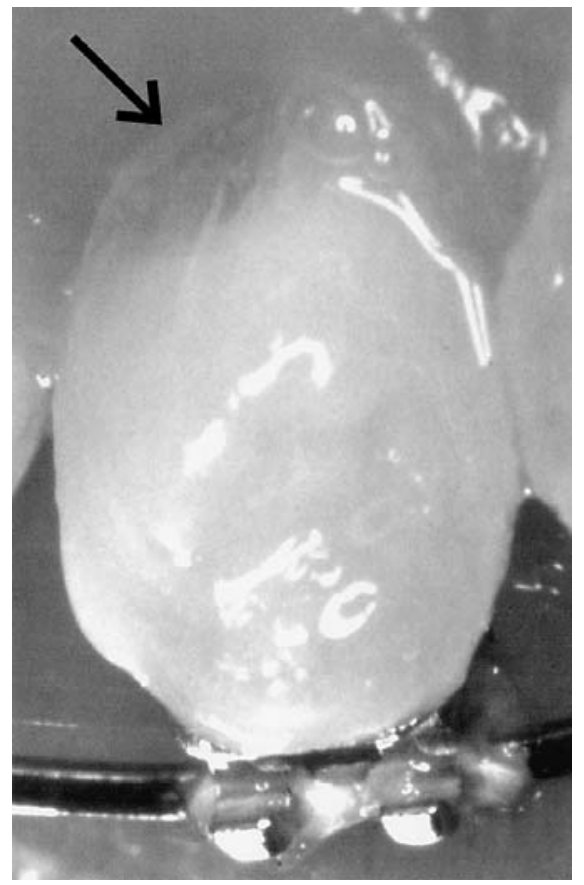

Fig. 1 Palatal view of the maxillary left lateral incisor of the present $15 \mathrm{Y} 10 \mathrm{M}$-old female at the first visit

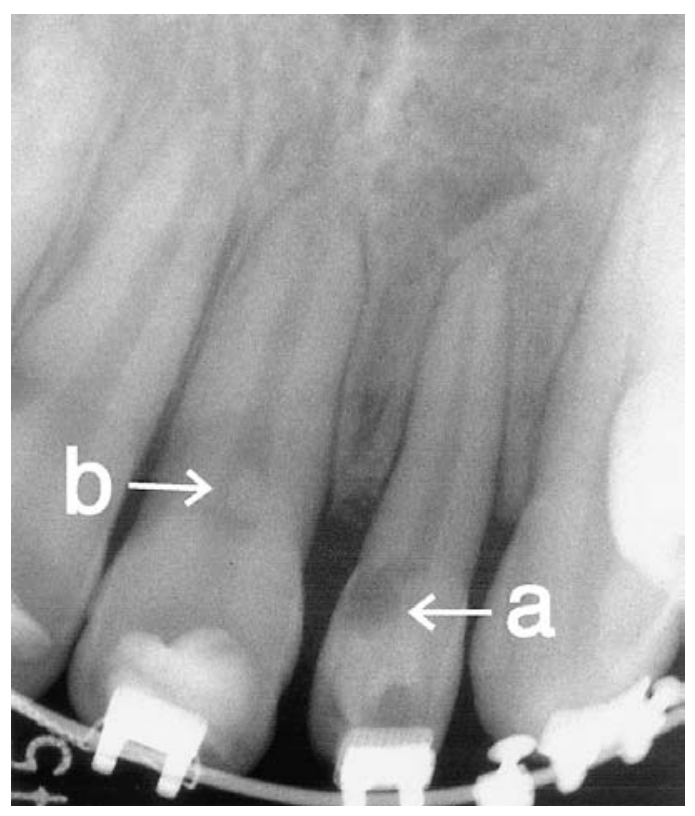

Fig. 2 Radiographic examination at the first visit A radiolucent area (a) and pulp stone (b) can be seen in the maxillary left lateral and central incisors, respectively. the affected tooth was a microdont with a large tubercle, with pink discoloration seen in the mesiopalatal area (Fig. 1). A periapical radiograph revealed resorption in the cervical area of the crown of the affected tooth (Fig. 2), which was positive in a vitality test, and there was no periodontal lesion visualized in the area around the tooth. However, a pulp stone was identified at the cervical third of the root of the adjacent central incisor and root resorption of the apex areas of nearly all of the teeth was also detected.

First, we removed the thin enamel from the affected tooth to confirm the lesion, which clarified the presence of granulation tissue below the area of pink discoloration (Fig. 3). Next, a pulpectomy was carried out using a conventional method, with calcium hydroxide paste $\left(V_{i t a p e x}{ }^{\circledR}\right)$ applied and glass-ionomer cement used to fill in the access cavity. At 1-month follow-up, the patient did not have any symptoms in the affected area and no abnormal findings were identified (Fig. 4). Thereafter, the root canal was filled with gutta-percha point by lateral condensation method, followed by the periodical examinations conducted at 3-month intervals for 3 years, and during this period further resorption could not be identified (Fig. 5).

\section{Discussion}

Internal resorption and external cervical resorption are commonly confused and misdiagnosed, however, since these are totally different pathological processes with different treatment protocols, correct diagnosis is essential ${ }^{9)}$. Fuss et al. ${ }^{10)}$ classified root resorption based on stimulation factors as pulpal infection resorption, periodontal infection resorption, orthodontic pressure resorption, impacted tooth or tumor pressure resorption, and ankylotic resorption. Our radiographic examination of the present patient did not show typical internal resorption, while it resembled that caused by a lesion associated with periodontal infection resorption, which is also termed cervical external resorption. An appropriate diagnosis of cervical external resorption is considered difficult, especially in cases where the lesion is located close to the gingival margin, which do not show external signs, but rather a pink discoloration of the tooth crown $^{7}$. Pink discoloration of the lingual surface of the affected tooth was seen in the present case, which indicated the presence of inflamed pulp tissue, and is characteristic of internal resorption. On the other hand, inflamed periodontal granulation tissue in cases of external resorption had been 


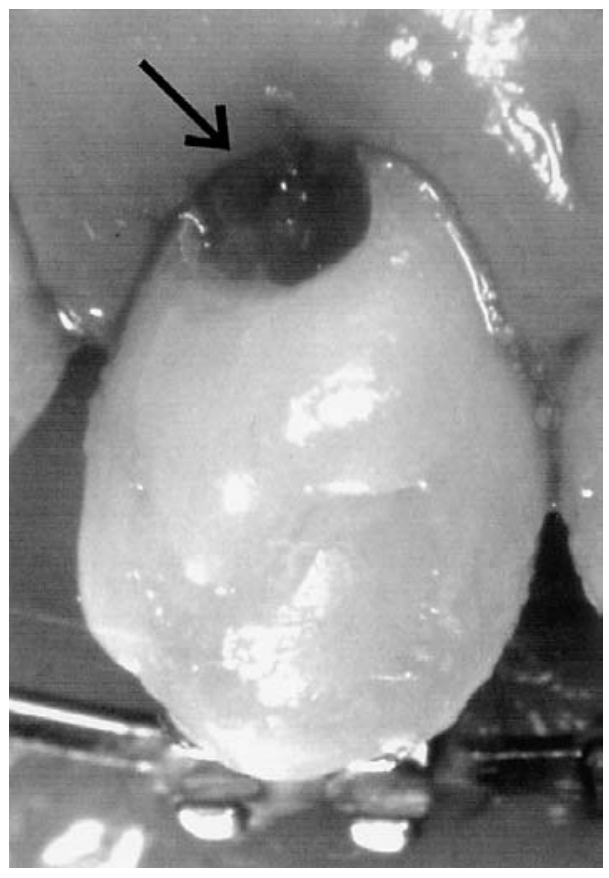

Fig. 3 Palatal view of the maxillary left lateral incisor after the thin enamel was removed

The arrow indicates the presence of granulation tissue.

reported to produce discoloration similar to that seen with internal resorption ${ }^{1}$. In the present case, there was no periodontal lesion identified and the radiolucent area was located at the tooth crown, which indicated that the resorption was not external but rather the internal resorption.

The cervical resorption was described as one of the possible complications in the patients with bone grafting of alveolar clefts, and the resorption is progressive in nature with a characteristic localization in the cervical area of the tooth ${ }^{11)}$. The possible etiologic factor of the resorption is regarded as the exposure and injury of the cementum tissue in the cervical region during the operation, especially the early cases before the age of $12^{12)}$. In addition, the cervical resorption was considered to be sometimes diagnosed several years after a combined surgical and orthodontic therapy in patients with cleft lip and palate ${ }^{13)}$. The frequency of the cervical resorption in the patients with bone grafting was reported to be approximately 5\% (15 teeth in 292 bone grafted cleft), of which 13 and 2 of the affected teeth was the canine and the lateral incisors, respectively ${ }^{14)}$. The bone grafting operation was carried out at the age of 10 in the present case, which may enhance the possibility of the cervical resorption.

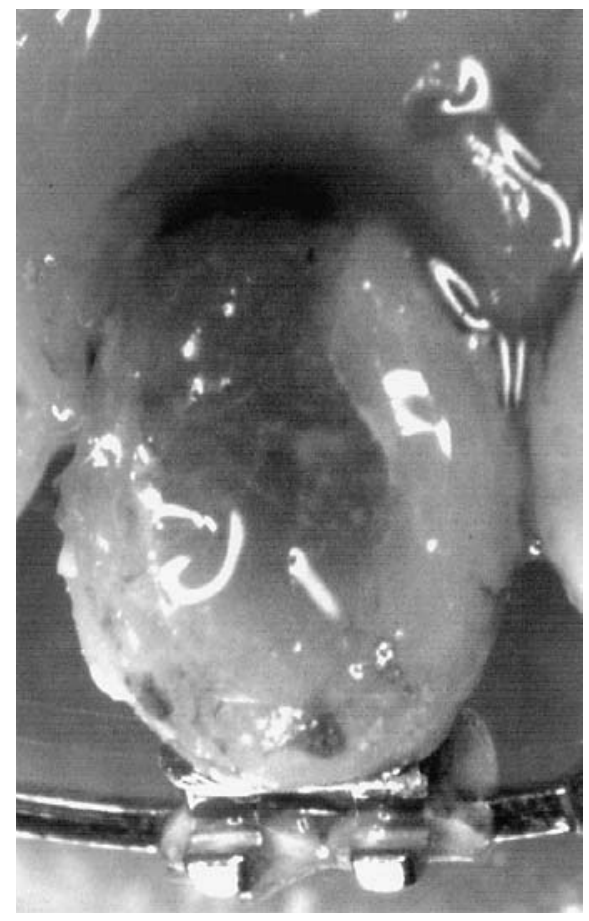

Fig. 4 Palatal view of the affected tooth 1 month after a pulpectomy procedure

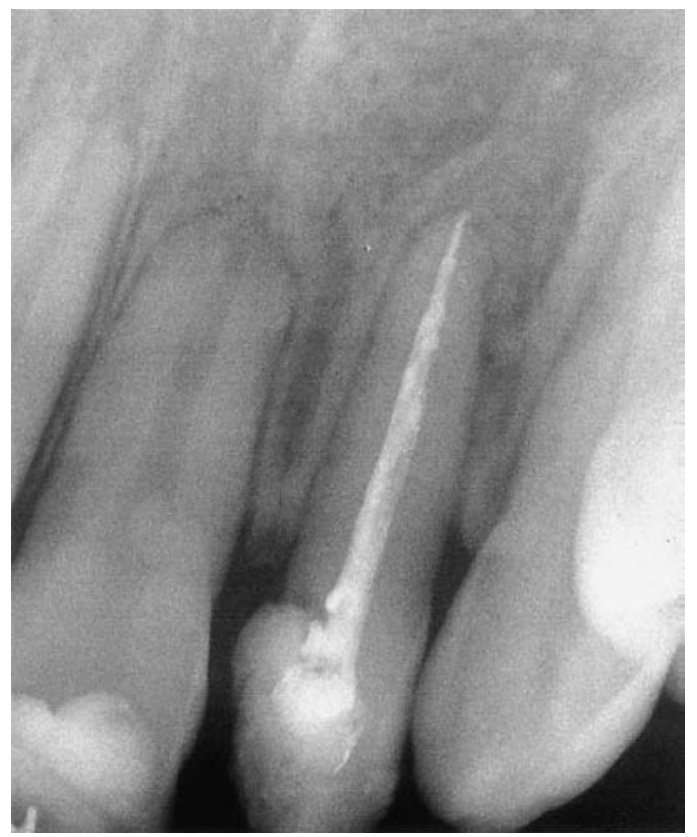

Fig. 5 Radiographic examination findings 2 years after the first visit

It has been suggested that internal resorption can occur as the result of trauma, infection of the dental pulp, and extreme heat ${ }^{3}$, however, it is difficult to 
speculate the etiologic factor of resorption in the present case. Kinomoto et al. ${ }^{15)}$ reported a case of internal resorption associated with inadequate caries removal and orthodontic therapy, which was concluded to be caused by irritation to the pulp tissue. There were no caries lesions identified in the present case, but the patient was undergoing orthodontic treatment at the initiation of resorption. In addition, the period of time when spontaneous pain was first recognized was consistent with the time when the orthodontist started to rotate the affected tooth. We concluded that there are several possible etiologic factors that may have caused resorption in the present case, among which orthodontic force might have been one of the important factors.

\section{References}

1) Ne, R.F., Witherspoon, D.E. and Gutmann, J.L.: Tooth resorption. Quintessence Int 30: 9-25, 1999.

2) Gunraj, M.N.: Dental root resorption. Oral Surg Oral Med Oral Pathol Oral Radiol Endod 88: 647653, 1999.

3) Trope, M.: Root resorption of dental and traumatic origin: classification based on etiology. Pract Periodontics Aesthet Dent 10: 515-522, 1998.

4) Heithersay, G.S: Clinical, radiologic, and histopathologic features of invasive cervical resorption. Quintessence Int 30: 27-37, 1999.

5) Tronstad, L.: Root resorption-etiology, terminology and clinical manifestations. Endod Dent Traumatol 4: 241-252, 1988.

6) Frank, A.L. and Torabinejad, M.: Diagnosis and treatment of extracanal invasive resorption. $J$ Endod
24: 500-504, 1998.

7) Bergmans, L., Van Cleynenbreugel, J., Verbekan, E., Wevers, M., Van Meerbeek, B. and Lambrechts, P.: Cervical external root resorption in vital teeth. $J$ Clin Periodontol 29: 580-585, 2002.

8) Patel, K., Darbar, U.R. and Gulabivala, K.: External cervical resorption associated with localized gingival overgrowth. Inter Endod J 35: 395-402, 2002.

9) Lyroudia, K.M., Dourou, V.I., Pantelidou, O.C., Labrianidis, T. and Pitas, I.K.: Internal root resorption studied by radiography, stereomicroscope, scanning electron microscope and computerized 3D reconstructive method. Dent Traumatol 18: 148-152, 2002.

10) Fuss, Z., Tsesis, I. and Lin, S.: Root resorptiondiagnosis, classification and treatment choices based on stimulation factors. Dent Traumatol 19: 175-182, 2003.

11) Gerner, N.W., Hurlen, B., Bergland, O., Semb, G. and Beyer-Oslen, E.M.: External root resorption in patients with secondary bone-grafting of alveolar clefts. Endod Dent Traumatol 2: 263-266, 1986.

12) Bergland, O., Semb, G. and Abyholm, F.E.: Elimination of the residual alveolar cleft by secondary bone grafting and subsequent orthodontic treatment. Cleft Palate J 23: 175-205, 1986.

13) De Moor, R.J., De Vree, H.M., Cornelis, C. and Boever, J.A.: Cervical root resorption in two patients with unilateral complete cleft of lip and palate. Cleft Palate Craniofac J 39: 541-545, 2002.

14) Bergland, O., Semb, G., Abyholm, F., Borchgrevink, H. and Eskeland G.: Secondary bone grafting and orthodontic treatment in patients with bilateral complete clefts of the lip and palate. Ann Plast Surg 17: 460-474, 1986.

15) Kinomoto, Y., Noro, T. and Ebisu, S.: Internal root resorption associated with inadequate caries removal and orthodontic therapy. J Endod 28: 405-407, 2002. 